Среднего Прикамья) // XI Тверской археологический сборник. Тверь: ТГОМ, 2018, С. 318-325.

15. Андреева (Ересько) О.В. Сравнительный анализ ранних энеолитических комплексов Среднего Прикамья и лесного Среднего Поволжья (на основе технико-технологического анализа) // Известия Самарского научного центра РАН. 2018. Т. 20, № 3. С. 208-215.

16. Андреева О.В., Батуева Н.С. Соотношение гончарных традиций камской и новоильинской культур // Вестник Научной ассоциации студентов и аспирантов Исторического факультета Пермского государственного педагогического университета. Серия:
Studia historica juvenum: науч. журн. Пермь: Перм. гос. пед. ун-т, 2018. С. 11-21.

17. Васильева И.Н. Ранненеолитическое гончарство Волго-Уралья (по материалам Елшанской культуры) // Археология, этнография и антропология Евразии. 2 (46). 2011. С. 70-81.

Работа выполнена при поддержке гранта РФФИ № 18-39-00059 «Ранние гончарные традиции населения Среднего Предуралья». Работа выполнена в рамках государственного задания Министерства образования и науки РФ, проект № 33.1907.2017ПЧ.

\title{
THE POTTERY TRADITIONS OF LEVSHINSKIY STAGE OF THE KAMA NEOLITHIC AND NOVOILYINSKAYA ENEOLITHIC CULTURES
}

(C) 2019

\author{
Andreeva Olga Viktorovna, laboratory assistant of Research Department \\ Samara State University of Social Sciences and Education (Samara, Russian Federation) \\ Batueva Nadezhda Sergeevna, specialist of Scientific Department \\ Perm State Humanitarian Pedagogical University (Perm, Russian Federation)
}

Abstract. The following paper deals with the complexes of the late (Levshin) stage of the Kama culture and the early Eneolithic ceramic complexes of the Novoilyinskaya culture of the Middle Prikamye within the framework of a historical-cultural approach to the study of pottery. In the course of the work, the most stable traditions of raw material selection were highlighted: silty clay was used for the Kama culture; clay and silty clay were used in equal shares for the manufacture of Novoilyinskaya ceramics. For the manufacture of Kama ceramics raw materials were initially dried and crushed; this tradition was absent in the Novoilyinskaya culture. In both cultures mostly unsprayed (ductile) raw materials were used. As a result, it turned out that the population of the Kama region of the early Eneolithic was formed on the basis of the genesis of the local Neolithic population - the Kama culture representatives with the new (Volga) population. This fact may be indicated by differences in the skills of preparing plastic raw materials, mineral impurities for the preparation of the molding material, as well as the methods of applying the ornament.

Keywords: archeology; Neolithic; Eneolithic; historical and cultural approach; technical and technological analysis; Prikamye; Kama culture; Levshin type; Novoilyinskaya culture; ornament; archaeological ceramics; raw plastic materials; molding composition; clay; silty clay; fireclay; organic solution.

УДК 902/904 (476)

DOI 10.24411/2309-4370-2019-12204

Статья поступила в редакцию 21.01.2019

\section{РОЛЬ КУЛЬТУРЫ ШАРОВИДНЫХ АМФОР В РАЗВИТИИ СООБЩЕСТВ ВЕРХНЕГО ПОНЕМАНЬЯ}

(C) 2019

Вайтович Александра Владимировна, кандидат исторических наук,

доцент кафедры археологии и специальных исторических дисциплин

Белорусский государственный университет (2. Минск, Республика Беларусь)

Аннотация. В статье обобщаются результаты исследований, проведенных автором и другими специалистами, по проблеме присутствия культуры шаровидных амфор (далее КША) на территории Верхнего Понеманья. В соответствии с подходом М. Шмит, разработанным для восточноевропейских комплексов культуры, в рассматриваемом регионе идентифицированы «чистые» и «синкретические» материалы КША. К первой группе отнесены могильники КША, кремнедобывающие шахты и сопутствующие мастерские в Среднем Пороссье, а также отдельные находки кремневых четырехгранных шлифованных топоров и долот. Во вторую группу включены материалы неманской культуры и локальных групп круга шнуровой керамики с элементами, генетически восходящими к КША. Черты КША прослеживаются главным образом в орнаментации керамики. Присутствие отдельных групп населения, традиций КША в Верхнем Понеманье относится ко второй четверти III - первой четверти II тыс. до н.э. Распространение элементов КША в регионе осуществлялось в результате непосредственных контактов носителей различных культурных традиций или опосредованно через другие культуры, которые уже испытали влияние КША. В качестве потенциальных источников распространения элементов КША рассматриваются среднеднепровская культура и приморская (жуцевская) культура. В настоящее время приоритетными исследовательскими задачами являются уточнение хронологии распространения КША в регионе, установление роли КША в социально-экономических трансформациях сообществ III - начала II тыс. до н.э.

Ключевые слова: культура шаровидных амфор; неманская культура; круг культуры шнуровой керамики; погребения; кремнедобывающие шахты; керамика; орнамент; кремневые топоры и долота; признаки культуры; традиции; культурные процессы; заимствования; производящее хозяйство; поздний неолит; Республика Беларусь; Верхнее Понеманье. 
Верхнее Понеманье занимает Гродненскую область, север Брестской и запад Минской областей Республики Беларусь. В гидрографическом отношении регион очерчен бассейном Немана и его основных притоков: Котры, Дитвы, Гавьи, Березины Неманской, Сулы, Свислочи, Росси, Зельвянки, Щары, Молчади. В III - начале II тыс. до н.э. этот регион представлял собой зону взаимодействия различных культурных традиций: «лесной неолитической» (неманская культура), «центральноевропейской» (культура шаровидных амфор и круг культуры шнуровой керамики), а также традиций, происходящих из Верхнего Поднепровья (среднеднепровская культура). В результате разнообразных культурных процессов формировались комплексы синкретического типа, которые представляли собой сложные структуры, образованные целым рядом культурных компонентов [1-3].

Проблема степени участия культуры шаровидных амфор (далее - КША) в культурных процессах, происходивших на территории Верхнего Понеманья в III - начале II тыс. до н.э., неоднократно привлекала внимание исследователей. Погребальные памятники этой культуры, сложившейся на пространствах от бассейна Эльбы до Повисленья, а впоследствии распространившейся в восточном и западном направлениях, были выявлены в рассматриваемом регионе в 1971 г. [4, с. $30-33 ; 5$, с. 17-18]. Первоначально, в первой половине 1970-х гг., специалисты предполагали, что КША не оказала существенного влияния на развитие автохтонных сообществ $[4$, с. $33 ; 6$, с. $19-$ 20]. К концу десятилетия появились данные о вкладе КША в формирование позднего, доброборского этапа неманской культуры [7, с. 63]. Во второй половине 1990-х гг. ученые пришли к выводу о том, что местное неолитическое население могло заимствовать у представителей КША как орнаментальные элементы [8, p. 433; 1, p. 136, fig. 44], так и производящее хозяйство и новые технологии добычи кремневого сырья $[9$, p. $97 ; 10$, с. $82 ; 11$, с. 216$]$. Начиная с рубежа тысячелетий стали появляться публикации, затрагивающие вопросы воздействия КША на локальные группы памятников круга культуры шнуровой керамики [2, с. $269 ; 3$, с. 148-152; 12, с. 14-15].

К настоящему времени накоплена представительная библиография по проблемам появления, распространения и существования КША в пределах рассматриваемого региона. Вместе с тем рост источниковедческой базы делает актуальным повторное обращение к вопросу о роли КША в развитии сообществ Верхнего Понеманья в период позднего неолита - начального периода бронзового века.

В новейшей литературе восточноевропейские материалы КША классифицируются на «чистые» (непосредственно связанные с КША) и «синкретические» (инокультурные комплексы, в которых зафиксированы отдельные черты КША) [1, p. 11, 120-126]. Подход, предложенный М. Шмит, получил развитие в работах белорусских исследователей [13; 11].

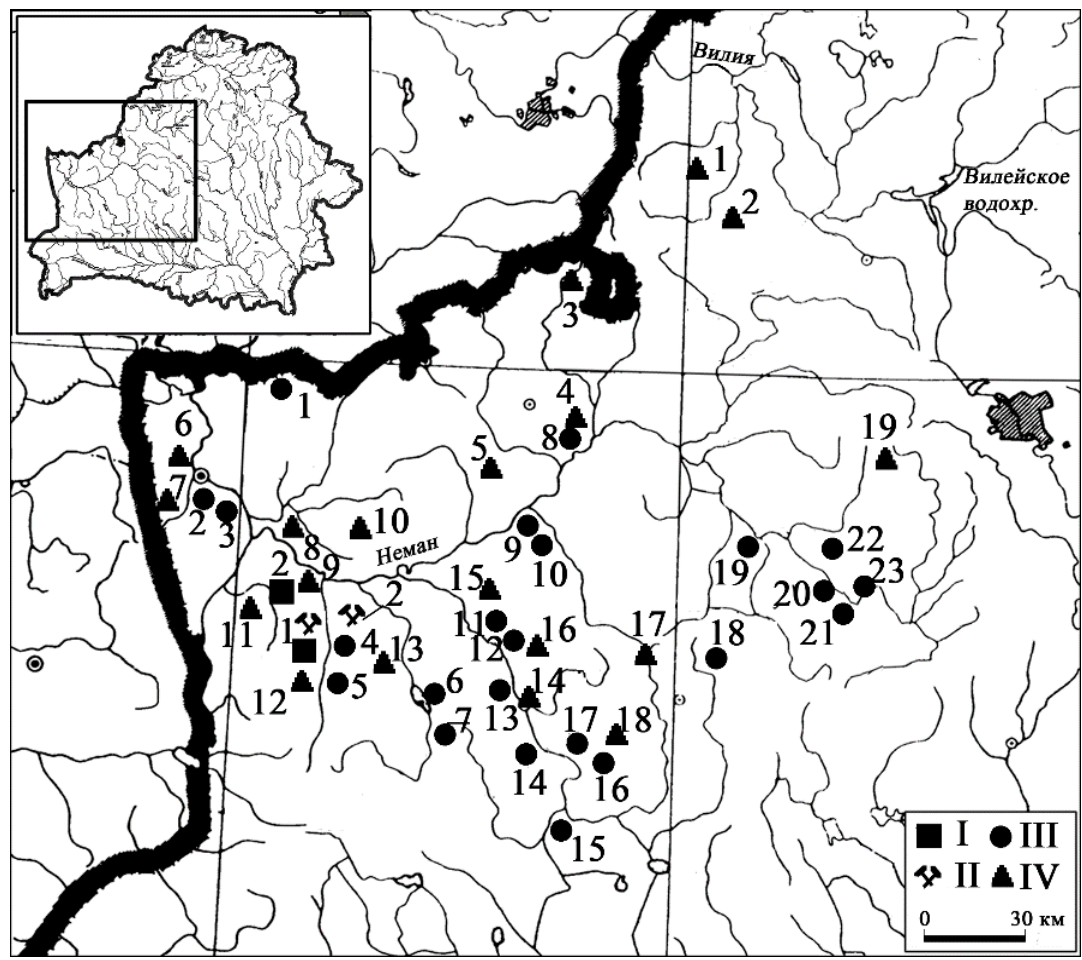

Рисунок 1 - Культура шаровидных амфор на территории Верхнего Понеманья.

I- погребальныя памятники культуры шаровидных амфор (1 - Красносельский; 2-Малые Едковичи); II- кремнедобывающие шахты и сопутствующие кремнеобрабатывающие мастерские (1- Красносельский; 2- Карповцы);

III- памятники с «синкретическими» материалами культуры шаровидных амфор

(1-Лихачи; 2-Жукевичи; 3-Стецки 1; 4-Красносельский 5; 5- Личицы 2; 6- Новоселки; 7- Цыгановка;

8- Докудово 5; 9 - Несиловичи 5; 10- Несиловичи 6; 11- Пархуты 1; 12- Пархуты 2; 13- Низ 2 (Яново 2);

14 - Русаково 2; 15- Добринево; 16- Подгорная 4; 17- Добрый Бор 1; 18- Старые Войковичи 1;

19-Яремичи 3; 20- Дрозды 12; 21 - Русаковичи 9; 22- Лысая Гора; 23- Миколаевщина 8);

$I V$ - местонахождения кремневых рубящих орудий с признаками культуры шаровидных амфор

(1- Ковали; 2- Кушляны; 3- Чирканцы; 4- Бурносы; 5-Глодовка; 6-Лососна; 7-Санники; 8- Лакно; 9-Лунно; 10 - Будровцы; 11 - Кубильники; 12 -Теолин; $13-$ Кременица;

14-Слоним; 15- Руда Яворская; 16- Подвеликое; 17- Нагорная; 18- Лесная; 19-Путчина) 
Вайтович А.В.

Роль культуры шаровидных амфор в развитии сообществ Верхнего Понеманья $\quad 07.00 .00$ - исторические науки и археология

В Верхнем Понеманье зарегистрирован ряд «чистых» форм присутствия КША (рис. 1: $I$ ). В регионе известны два погребальных памятника КША: могильник около поселка Красносельский в среднем течении реки Россь (рис. 2) и единичное погребение возле деревни Малые Едковичи в бассейне реки Свислочь $[4$, с. $30-33 ; 5$, с. $17-18 ; 11$, с. $211-215 ; 1$; 14]. К памятникам производственной деятельности носителей рассматриваемой культуры следует отнести шахты и сопутствующие мастерские, расположенные на меловых линзах Пороссья - в окрестностях поселка Красносельский и деревни Карповцы (рис. 1: II). Основной специализацией кремнедобывающего центра было производство заготовок топоров и долот. На современном этапе исследований представления об участии в добыче и обработке кремня представителей КША обосновываются следующими данными: 1) расположение на одной из меловой линз могильника культуры $[10$, с. 75-82; 11 , c. 219]; 2) соответствие технологических, метрических и стилистических признаков заготовок стандартам кремневой индустрии КША. Артефакты, характерные для КША, зафиксированы на всех исследованных участках кремененосного района $[15 ; 16$, s. 44-46; 12 , c. $8 ; 17$, с. 157-158]. Вместе с тем необходимо учитывать, что носители КША представляли собой только одну из нескольких групп населения, занимавшихся добычей и обработкой кремня в Красносельском микрорегионе [18, с. $128 ; 10$, с. $75-84$; 11$, c. $219 ; 19$, c. $122-124 ; 17$, c. $157-158]$.

Дискуссионным вопросом является проблема идентификации поселенческих памятников КША на территории Верхнего Понеманья. В литературе отмечено поселение КША в районе кремнедобывающих выработок (Красносельский 5) [10, с. 56-61; 20, c. 37]. Кроме того, исследователи неоднократно идентифицировали единичные фрагменты керамики КША в коллекциях ряда многокультурных памятников региона $[6$, с. $19 ; 9$, p. 96-97, fig. $7 ; 10$, с. $82 ; 11$, c. $215 ; 1$, p. $256-257,259$, fig. 49 : 7; fig. $52: 11-15 ; 16$, s. $17 ; 3$, c. 51, 68]. С другой стороны, эти же артефакты рассматриваются и в контексте древностей круга культуры шнуровой керамики (см., напр., [6, с. 19; 12 , с. 14-15]). Такая ситуация обусловлена сложностями дифференциации «амфорной» и локальной «шнуровой» керамики, обладавшей рядом схожих технологических и орнаментальных признаков.
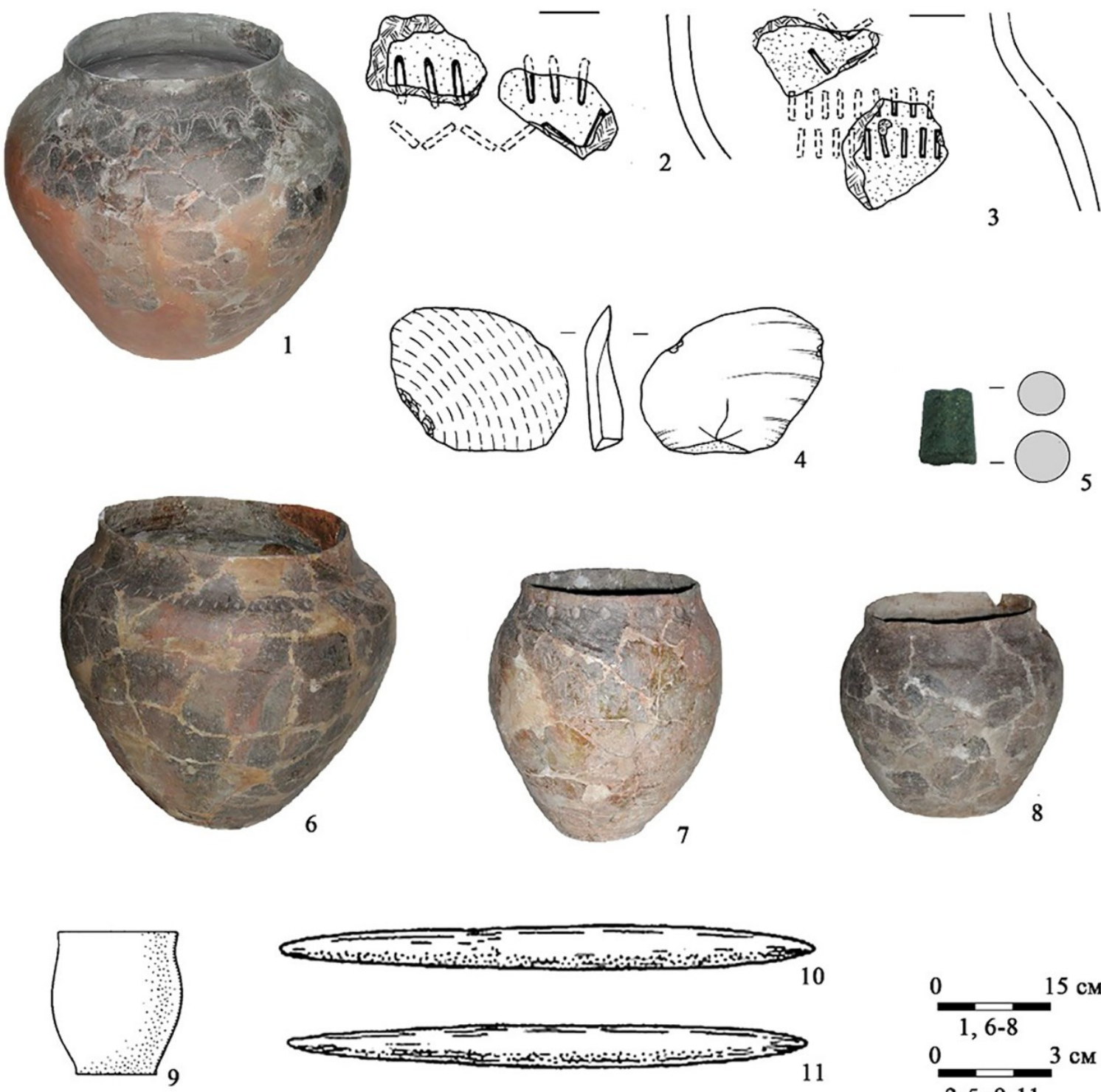

10

11

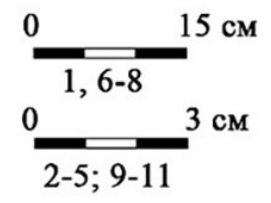

Рисунок 2 - Инвентарь погребений Красносельского могильника культуры шаровидных амфор: 1- погребение 1; 2-5- погребение 2; 6-11- погребение 3 (1-3, 6-9-керамика; 4- кремневый отщеп; 5- высверлина от каменного топора; 10, 11 - костяные наконечники) (1-8- фото и рисунки автора; 9-11- по Чарняўскі [11, рис. 92: 2, 3, рис. 93: 2]) 
Наконец, проблематичным остается отнесение к категории «чистых» материалов случайных находок кремневых топоров и долот, соответствующих стандартам КША, но не связанных с конкретным культурным контекстом (рис. 1: $I V$ ). К настоящему времени в регионе зарегистрировано около 20 местонахождений кремневых трапециевидных топоров четырехгранного поперечного сечения, зашлифованных по всей поверхности и заполированных в прилезвийной части, а также прямоугольных или трапециевидных в плане шлифованных долот (рис. 3) [6, c. $19 ; 8$, p. $434 ; 9$, p. $97 ; 11$, c. $215 ; 1$, p. $261-265 ; 21$; 16 , s. $23,42-43,38,83 ; 22$, c. $17,19-20,22 ; 12$, c. 9 10]. Технико-морфологические характеристики таких рубящих орудий находят аналогии в инвентаре КША, однако с учетом того, что схожие изделия встречаются и в комплексах ряда синхронных культур (см., напр., [23]), предполагается, что находки такого типа следует объединять с КША гипотетически $[1$, р. 11, 123-124; 20, с. 34].
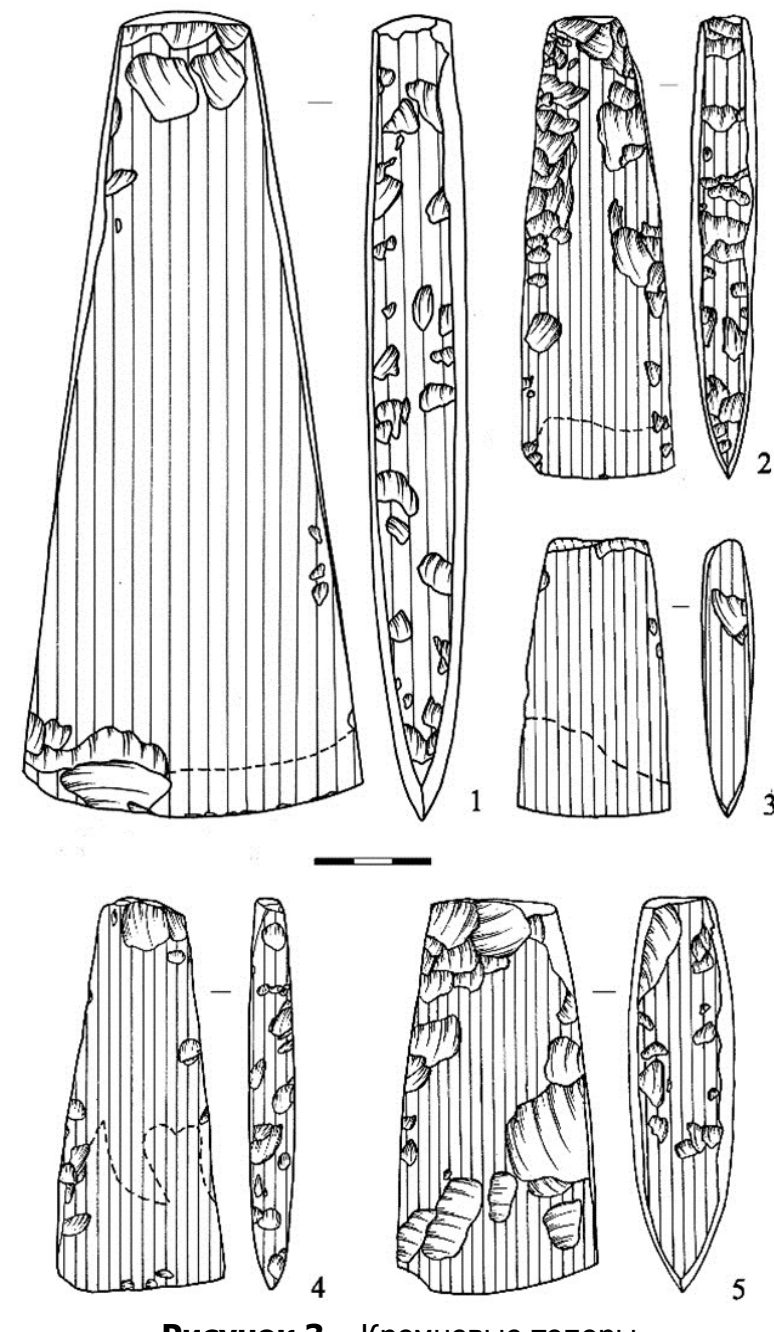

Рисунок 3 - Кремневые топоры

с признаками культуры шаровидных амфор: 1-Путчина; 2- Лососна; 3-Санники;

4- Слоним; 5- Кременица (рисунки автора)

Согласно современным представлениям, носители КША начали осваивать территорию Верхнего Понеманья после 2900 г. до н.э. В настоящее время имеется одна радиоуглеродная дата, полученная по костным остаткам животных из погребения 3 Красносельского могильника - 2830-2450 ВС (2580 ВС) (Gd- 9249) [1, p. 66]. Специалисты, анализируя инвентарь погребальных памятников, прослеживают связи мигрантов с центральной группой культуры, в частности с мазовецко-подлясской подгруппой [1, p. 42; 20, с. 37] и малопольской и люблинской подгруппами $[14$, с. $7-99 ; 12$, с. 10]. Вероятно, новое население было заинтересовано в разработке залежей высококачественного мелового кремня в Среднем Пороссье.

Скорее всего, в Верхнее Понеманье проникали сравнительно немногочисленные группы населения [1, p. 197; 20, с. 37]. Данные, свидетельствующие о заимствовании мигрантами «лесных неолитических» черт, в настоящее время ограничены [1, р. 197-198; 20, c. 46]. Более дискуссионной является проблема взаимодействия представителей КША и локальных «шнуровых» групп. В погребении № 2 Красносельского могильника КША находилась высверлина от каменного сверленого топора (рис. 2: 5) [11, с. 212; 12, с. 11]. Присутствие в погребении артефакта, характерного для круга культуры шнуровой керамики, может быть объяснено двумя альтернативными гипотезами: 1) такая находка - свидетельство заимствования носителями КША новых идей и практик в результате непосредственных контактов с представителями иных культурных традиций. Сосуществование двух разных «центральноевропейских» групп в Красносельском микрорегионе подтверждается размещением на меловых линзах и могильника КША и «шнурового» «погребения шахтера» $[18$, с. $128 ; 10$, c. $75-84 ; 11$, с. $219 ; 24$, с. 308-309]; 2) артефакт попал в заполнение погребения случайно (во время засыпки могилы либо под действием постдепозиционных процессов). В любом случае, как полагают специалисты, представители КША, оказавшись в чуждом культурном окружении, хотели подчеркнуть свои культурные особенности и укрепить групповую идентичность. Эти стремления выражались в выполнении сложных ритуальных практик, наиболее ярким примером которых является погребение 3 Красносельского могильника - богатое захоронение животных [1, p. 198].

Второй, гораздо более массовой формой присутствия КША на территории Верхнего Понеманья являются материалы синкретического типа (рис. 1: III). Они фиксируются в материалах как неманской культуры $[7$, с. 63,$78 ; 25$, с. $153 ; 1$, p. 136 ; fig. $44 ; 20$, с. 38 ; 12, с. 11-12; 26, p. 249], так и локальных групп круга культуры шнуровой керамики [2, с. $269 ; 3$, с. 148-152; 12 , c. $14-15 ; 26$, p. 251-256; 27, p. 119-120].

Элементы КША в контексте «лесного неолита» Понеманья сравнительно немногочисленны (рис. 4: 1-3). В 1980-1990-х гг. исследователи предполагали, что носители позднего, доброборского, этапа неманской культуры могли заимствовать у центральноевропейских мигрантов традицию штрихования (притирания травой) поверхностей керамики [25, с. 153] и практику добавления в глиняное тесто дресвы [8, p. 432-433]. Однако такие утверждения не нашли поддержки в новейшей литературе [20, с. 38]. Согласно актуальным представлениям, черты КША прослеживаются только в орнаментации керамики. На посуде неманской культуры зафиксирован декор в виде горизонтальных рядов вертикальных отпечатков линейного штампа и зигзага, нанесенного штампом, а также «трубчатого» орнамента (группы A1, A2 по классификации М. Шмит [1, p. 120-121]). Вместе с тем наблюдается некоторая трансформация «амфорных» традиций. Характерный для КША орнамент часто наносился в «скорописной» манере, из- 
Вайтович А.В.

Роль культуры шаровидных амфор в развитии сообществ Верхнего Понеманья $\quad 07.00 .00$ - исторические науки и археология

вестной в неманской культуре уже на предшествующем, лысогорском, этапе [7, с. 59]. «Амфорные» мотивы часто сочетались с декором, типичным для «лесного неолита», например, ямочными вдавлениями, наколами «отступающей» лопаточки и др. Орнаменты, восходящие к КША, присутствуют в материалах поселений неманской культуры в бассейнах рек Щара и Россь.

Значительно более выразительный «амфорный» компонент отмечается в локальных группах круга культуры шнуровой керамики. Черты КША зарегистрированы в материалах и поселений (рис. 4: 4-16), и погребений (рис. 5). В подавляющем большинстве случаев элементы КША фиксируются в орнаментации керамики. Для украшения посуды понеманскими «шнуровиками» использовались отпечатки линейно-
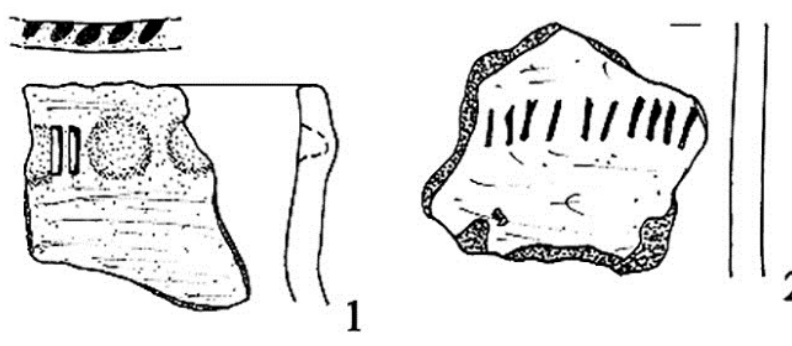

2

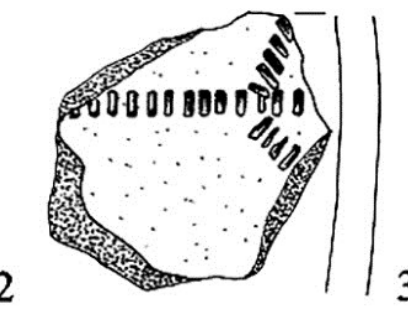

\section{- inmminm,}
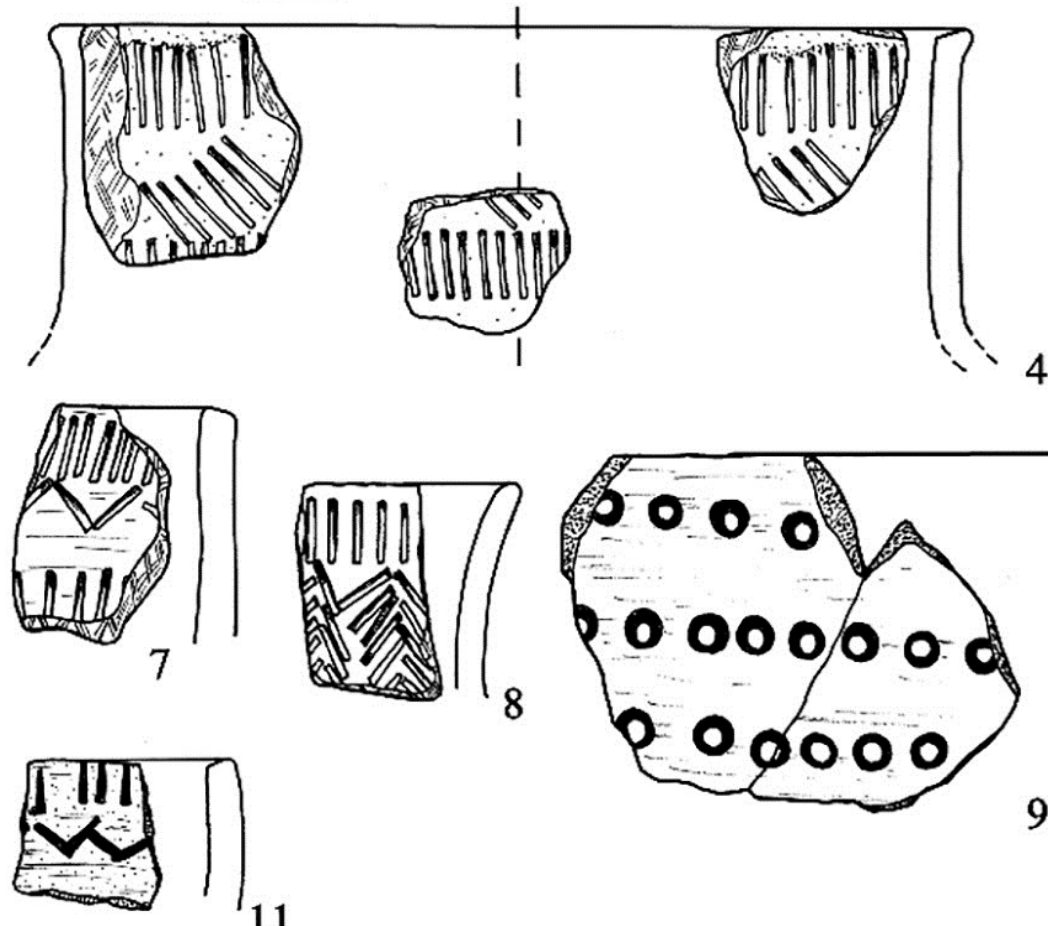

9
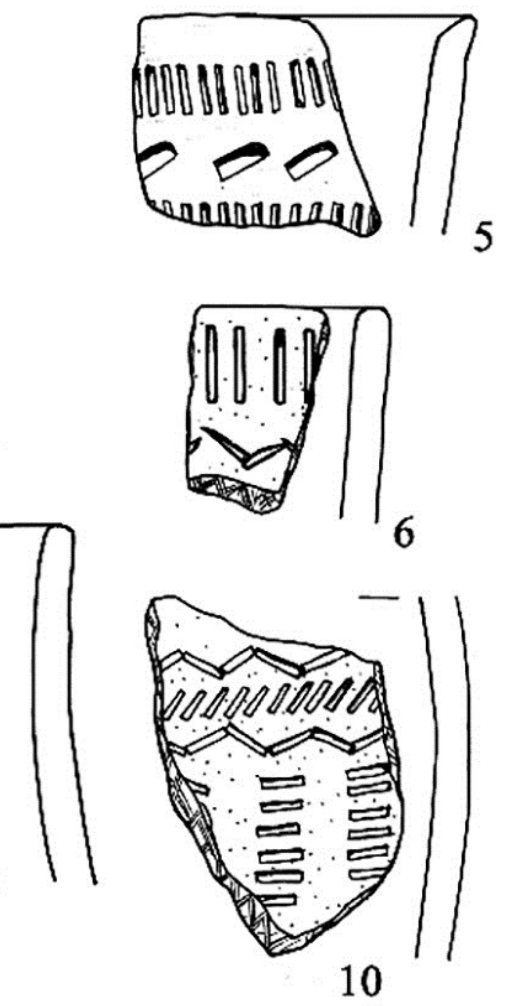

11

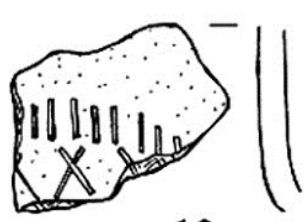

12
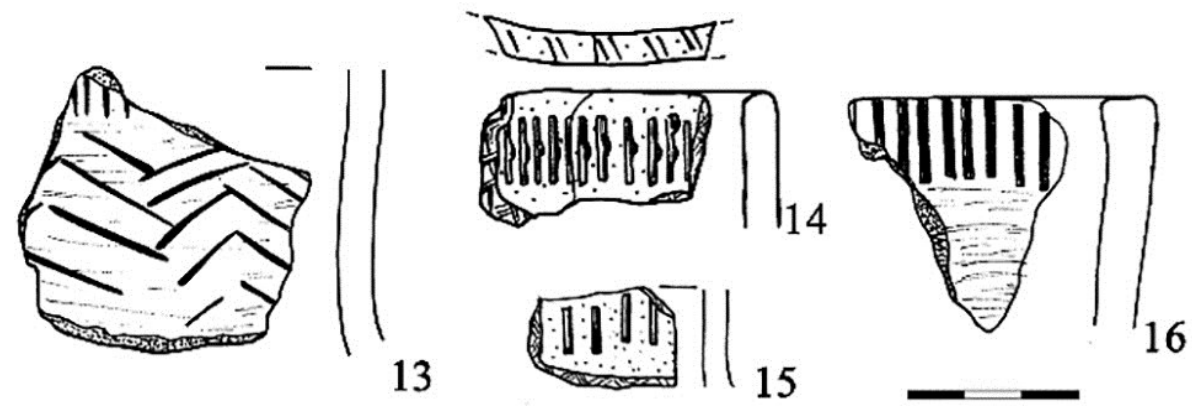

Рисунок 4 - Керамика неманской культуры (1-3) и памятников круга культуры шнуровой керамики на территории Верхнего Понеманья (4-16) с признаками культуры шаровидных амфор:

1, 10, 14- Красносельский 5; 2, 3- Старые Войковичи 1; 5-9, 13, 15- Русаково 2; 4, 12 - Лысая Гора; 11 - Миколаевщина 8; 16-Яремичи 3 (рисунки автора) 

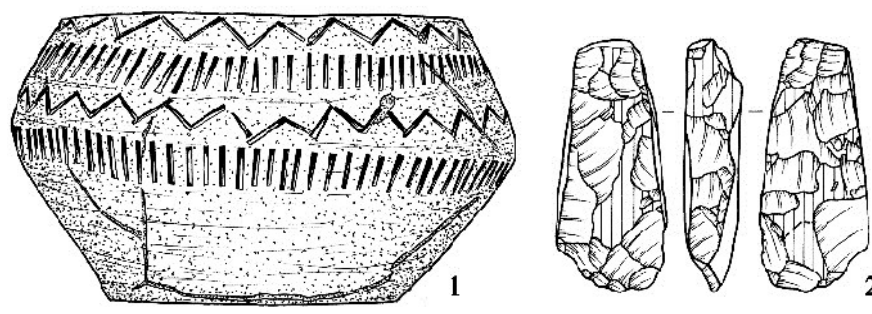

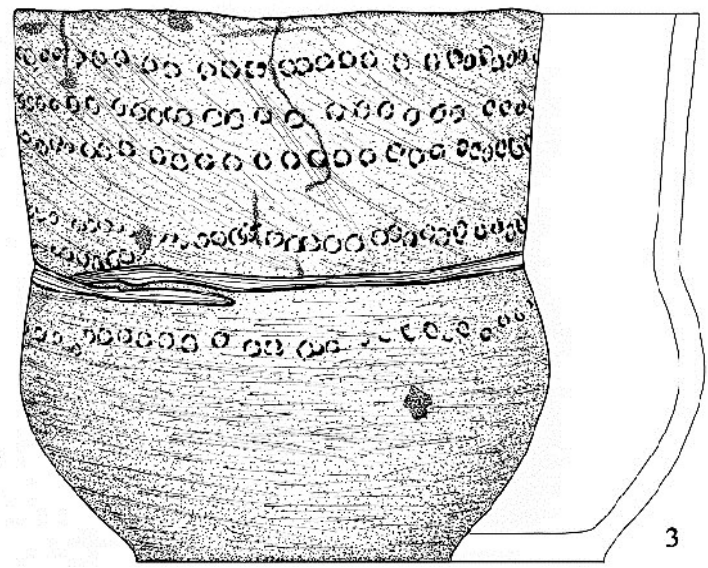

Рисунок 5 - Инвентарь погребений круга культуры шнуровой керамики на территории Верхнего Понеманья с признаками культуры шаровидных амфор: 1, 2- Низ 2 (Яново 2); 3- Дрозды 12 (рисунки автора)

Установление времени распространения черт КША в регионе усложняется общей неразработанностью абсолютной хронологии и периодизации неманской культуры и локальных групп круга культуры шнуровой керамики. Минимальные хронологические рамки существования неманской культуры на территории Западной Беларуси определяются периодом 3600-2900 гг. до н.э., однако более вероятная верхняя граница существования культуры относится ко второй четверти II тыс. до н.э. [28, р. 109]. Функционирование «шнуровых» групп на территории Верхнего Понеманья датируется второй четвертью III - ceрединой второй четверти II тыс. до н.э. [3, с. 147-155].

Современное состояние изученности проблемы позволяет утверждать, что восприятие традиций КША населением Верхнего Понеманья происходило несколькими путями. Безусловно, могли иметь место прямые контакты отдельных представителей КША и носителей «лесных неолитических» и «шнуровых» групп. Также вполне возможно, что элементы КША распространялись в местной культурной среде посредством других культур, которые уже испытали «амфорное» воздействие. Наиболее вероятными источниками поступления традиций и идей КША в понеманские «шнуровые» группы могли являться жуцевская (приморская) культура Циркумбалтийского культурного круга и среднеднепровская культура, а также группа шнуровой керамики полесского типа. Эти культуры, вобравшие многие «амфорные» черты $[1$, p. $175-178 ; 29 ; 13$, с. $76-79 ; 30 ; 31$, с. 210$]$, оказали существенное влияние на культурное развитие изучаемого региона $[24$, с. $307-311 ; 32$, с. 20-21; 3 , c. 147-155]. Более проблематичным является установление истоков «амфорных» элементов в материалах «лесного неолита». С одной стороны, в роли посредников в распространении элементов КША в неманской культуре могли выступать локальные группы круга культуры шнуровой керамики. В литературе неоднократно отмечалось, что местное неолитическое население заимствовало некоторые «шнуровые» традиции $[25$, с. $153 ; 24$, с. 310$]$. С другой стороны, необходимо учитывать и то, что в рассматриваемом регионе орнамент в виде отпечатков линейного штампа появился в среднем неолите - на лысогорском этапе неманской культуры под воздействием культуры воронковидных кубков [7, с. 58-59; 1, p. 120-121; 33]. Таким образом, нельзя исключать вероятности того, что украшение поздненеолитической неманской керамики отпечатками линейного штампа является дальнейшим развитием воспринятых на предшествующем этапе «центральноевропейских» традиций. Вместе с тем широкое распространение линейного штампа происходило в III тыс. до н.э., что могло являться результатом влияния именно КША.

Малоизученным является вопрос о роли КША в культурных трансформациях, происходивших на территории изучаемого региона в период перехода от неолита к эпохе бронзы. Специалисты предполагают, что некоторые «амфорные» традиции принимали участие в формировании локальных групп тшинецкого культурного круга [3, с. 158]. Наличие пережиточных «амфорных» черт отмечается во многих комплексах, выявленных в разных регионах тшинецкого ареала $[34 ; 35$, s. 116-122; 1, р. 199; 36, s. 115; 12, с. 17]. Детальный таксономический анализ, направленный на идентификацию элементов КША в тшинецких материалах Верхнего Понеманья, остается перспективной исследовательской задачей.

Необходимо также учитывать, что носителям изучаемой культуры принадлежала определенная роль в распространении производящего хозяйства в рассматриваемом регионе. Имеющиеся данные свидетельствуют о том, что население «лесного неолита» могло познакомиться с земледелием на этапах, предшествовавших позднему неолиту, однако возрастание роли земледелия и укоренение животноводства происходило в III тыс. до н.э. - в период распространения «амфорных» и «шнуровых» традиций $[37$, с. $12-14 ; 38 ; 39$, с. 46-47]. Судя по материалам Красносельского могильника, в состав стада представителей КША входил крупный и мелкий рогатый скот, свиньи, лошади [40, с. 627-629]. В сосуде, выявленном в погребении круга культуры шнуровой керамики на памятнике Дрозды 12 и украшенном орнаментом, генетически восходящим к КША (рис. 5: 3), хранились продукты, содержащие жир жвачных животных [41, р. 548-549]. Тем не менее, сосуществуя с группами населения, применявшими развитые аграрные технологии, представители неманской культуры сравнительно долго сохраняли архаичный уклад жизни, ориентируясь на занятия охотой, рыболовством и собирательством. На современном этапе развития науки вопрос о конкретном вкладе носителей КША в эволюцию хозяйственных занятий понеманских сообществ «лесного неолита» попрежнему остается открытым. 
В специальной литературе неоднократно высказывалось и предположение о том, что местное неолитическое население могло заимствовать у мигрантов навыки добычи кремня шахтовым способом $[9$, р. $97 ; 10$, с. $82 ; 11$, с. 216]. Вместе с тем, согласно актуальным представлениям, данные об участии носителей неманской культуры в эксплуатации шахт и мастерских Красносельского микрорегиона отсутствуют $[15 ; 19 ; 17]$. Более перспективными являются поиски свидетельств взаимодействия в сфере добычи кремня и организации производства сообществ КША и круга культуры шнуровой керамики [19, с. 122-124].

Несомненно, представители КША принимали активное участие в обеспечении функционирования коммуникационных и обменных путей и контактов, которые связывали Верхнее Понеманье с различными регионами. Возле деревни Кубильники Берестовицкого района был найден топор из «полосатого» кремня, месторождения которого расположены около Кшеменок Опатовских на территории современной Польши $[10$, c. $82 ; 1$, pl. 60: 11]. В этом микрорегионе продолжительное время действовали кремнедобывающие шахты и кремнеобрабатывающие мастерские КША. Мастера кшеменковского производственного центра специализировались на изготовлении кремневых четырехгранных топоров, которые посредством различных механизмов распространялись на расстояние свыше 500 км [42, ryc. 44]. Вероятно, благодаря носителям КША осуществлялся экспорт кремневых рубящих орудий, сделанных в кремнедобывающем центре в Среднем Пороссье. Специалисты предполагают, что значительная часть четырехгранных топоров и долот, характерных для КША и выявленных на территории северной, восточной и центральной Польши, а также в ряде регионов Литвы и Латвии, изготовлена из неманского мелового кремня [15, s. 105; 19 , c. 123]. Сейчас невозможно реконструировать систему обмена, в рамках которой происходило распространение артефактов. Скорее всего, основными дорогами, по которым осуществлялось движение изделий, являлись речные пути - Россь и Неман [19, с. 123].

Таким образом, на территории Верхнего Понеманья отмечаются как материалы собственно культуры шаровидных амфор, так и отдельные «амфорные» элементы в составе комплексов «синкретического» типа. Элементы, генетически восходящие к КША, зафиксированы в контексте и неманской культуры, и локальных групп круга культуры шнуровой керамики. Заимствование «амфорных» черт, традиций и идей происходило в результате разнообразных ситуаций. С одной стороны, нельзя исключать возможности непосредственных контактов пришлого и местного населения. С другой стороны, вполне возможно, что «амфорные» элементы проникали в регион в качестве компонентов других экзогенных культур, уже находившихся под влиянием КША. Моделирование механизмов передачи «амфорных» культурных традиций и определение характера контактов групп древнего населения требует проведения дальнейших исследований. Актуальным направлением изысканий по-прежнему остается разработка детальной хронологии распространения элементов КША в регионе. Наконец, перспективной задачей является определение роли КША в социально-экономической трансформации сообществ III - начала II тыс. до н.э.

\section{Список литературы:}

1. Szmyt M. Between West and East. People of the Globular Amphora Culture in Eastern Europe : 29602350 BC // Baltic-Pontic Studies. 1999. Vol. 8. 350 p.

2. Крывальцэвіч M.M. «Шнуравы гарызонт» на Беларусі: праблемы ідэнтыфікацыі і генезіса // Od neolityzacji do początków epoki brązy. Przemiany kulturowe w międzyrzeczu Odry i Dniepru między VI i II tys. przed Chr. Archaeologia Bimaris. T. 2 / red. J. Czebreszuk, M. Kryvaltsevič, P. Makarowicz. Poznań: Wyd. Poznańskie, 2001. S. 259-275.

3. Лакіза В.Л. Старажытнасці позняга неаліту i ранняга перыяду бронзавага веку Беларускага Панямоння. Мінск: Беларуская навука, 2008. 344 с.

4. Чарняўскі М.М. Могільнік на Росі // Помнікі гісторыі і культуры Беларусі. 1972. № 4. С. 30-33.

5. Кавальская К., Чарняўскі М. Старажытнае пахаванне // Помнікі гісторыі і культуры Беларусі. 1988. № 4. C. 17-18.

6. Исаенко В.Ф. Археологическая карта Белоруссии. Вып. 3: Памятники бронзового века. Минск: Полымя, 1976. 150 с.

7. Чарняўскі М.М. Неаліт Беларускага Панямоння. Мінск: Навука і тэхніка, 1979. 142 с.

8. Černiawski M. The Neolithic in North-Western Byelorussia // Neolit i początki epoki brązy na ziemi Chełmińskiej: materiały z międzynarodowego sympozjum. 11-13 listopada 1986 r., Toruń, Polska / red. T. Wiślański. Toruń: UMK, 1987. S. 429-441.

9. Charniauski M. Materials of the Globular Amphora Culture in Belorus // Baltic-Pontic Studies. 1996. Vol. 4: Eastern Exodus of the Globular Amphora People: 2950-2350 ВC. Р. 87-98.

10. Чарняўскі М.М., Кудрашоў В.Я., Ліпніцкая В.Л. Старажытныя шахцёры на Росі. Мінск: Навука і тэхніка, 1996. 144 с.

11. Чарняўскі М.М. Культура шарападобных амфар // Археалогія Беларусі: у 4 т. Т. 1: Каменны і бронзавы вякі / пад рэд. М.М. Чарняўскага [і інш.]. Мінск: Беларуская навука, 1997. С. 211-219.

12. Зуева А.У. Культура шарападобных амфар на тэрыторыі Беларусі і яе роля ў развіцці супольнасцяў III - пачатку II тыс. да н.э.: аўтарэф. дыс. ... канд. гіст. навук. Мінск, 2011. 24 с.

13. Крывальцэвіч М.М. Могільнік сярэдзіны IIIII тыс. да н.э. на Верхнім Дняпры - Прорва-1. Мінск: ІГ НАНБ, 2006. $202 \mathrm{c}$.

14. Зуева А.У. Паўночна-ўсходнія могільнікі культуры шарападобных амфар і іх месца ў «амфарнай» культурнай прасторы // Гістарычна-археалагічны зборнік. 2007. Вып. 23. С. 82-100.

15. Barska K. Nowe dane dotyczące powiązań kopalni krzemenia w Krasnym Siole z kulturą amfor kulistych // Badania archeologiczne w Polsce północznowschodniej i na zachodniej Białorusi w latach 2000-2001: materiały z konferencji. 6-7 grudnia 2001 r., Białystok / red. M. Karczewska, M. Karczewski. Białystok: Instytut Historii Universitetu w Białymstoku, 2002. S. 101-110.

16. Obuchowski W. Zabytki krzemienne i kamienne od paleolitu do wczesnej epoki żelaza z terenów Białorusi w zbiorach Państwowego Museum Archeologicznego w Warszawie. Warszawa: Wyd. PMA, 2003. 208 s.

17. Вайтович А.В. Кремневые рубящие орудия из шахт и мастерских около деревни Карповцы в Белорусском Понеманье: технология производства и культурно-хронологическая идентификация // Древний человек и камень: технология, форма, функция / 
отв. ред.: С.А. Васильев, В.Е. Щелинский. СПб.: Петербургское востоковедение, 2017. С. 152-164.

18. Гурина Н.Н. Древние кремнедобывающие шахты на территории СССР. Л.: Наука, 1976. 178 с.

19. Пиличаускас Г. Кремневые шлифованные топоры с территории Беларуси из собрания Национального музея Литвы в контексте новых исследований подобных находок в юго-восточной Прибалтике // Acta Archaeologica Albaruthenica. 2008. Vol. 3. C. 118-139.

20. Чебрешук Я., Шмит М. К исследованию среднеевропейских факторов процесса культурных перемен в лесной зоне восточной Европы в третьем тысячелетии до н.э. // Гістарычна-археалагічны зборнік. 2003. № 18. С. 34-51.

21. Абухоўскі В.С. Матэрыялы каменнага і бронзавага вякоў 3 ваколіц маёнтка Антонава былога Слонімскага павета // Слонімшчына вачыма навукоўцаў і краязнаўцаў: матэрыялы рэгіянальнай гісторыка-краязнаўчай канферэнцыі, прысвечанай 750годдзю г. Слоніма і 70-годдзю заснавання Слонімскага раённага краязнаўчага музея імя I.I. Стаброўскага / склад.: Д.С. Аляшкевіч, І.П. Крэнь. Слонім: Слонімская друкарня, 2002. С. 44-49.

22. Абухоўскі В.С., Зуева А.У., Сідаровіч В.М. Чатырохбаковыя крамянёвыя шліфаваныя сякеры ў зборы Нацыянальнага музея гісторыі і культуры Беларусі // Acta Achaeologica Albaruthenica. 2008. Vol. III. C. 17-41.

23. Libera J. Czy siekiery krzemienne mogą być wyznacznikiem kultury amfor kulistych? // Hereditas praeteriti. Additamenta archaeologica et historica dedicata Ioanni Gurba Octogesimo Anno Nascendi / pod red. H. Taras i A. Zakościelnej. Lublin: Uniwersitet M. Curie-Scłodowskiej, 2009. S. 169-179.

24. Чарняўскі M.M. Культура шнуравой керамікі Панямоння // Археалогія Беларусі: у 4 т. Т. 1: Каменны і бронзавы вякі / пад рэд. М.М. Чарняўскага [i інш.]. Мінск: Беларуская навука, 1997. С. 307-311.

25. Чарняўскі М.М., Ісаенка У.Ф. Нёманская культура // Археалогія Беларусі: у 4 т. Т. 1: Каменны i бронзавы вякі / пад рэд. М.М. Чарняўскага [i інш.]. Мінск: Беларуская навука, 1997. С. 145-170.

26. Vaitovich A. Die Rolle der Kugelamphorenkulturbei der Entwicklung der Gesellschaftenim Gebiet des oberen Njemen während des dritten und zu Beginn des zweiten Jahrtausends v. u. Z. Lehren-SammelnPublizieren. Dem Hochschullehrer, Museumsmann und Verleger Hans-JügenBeierum 60. Geburtstagvon Freunden und Kollegengewidmet. // J. Beran et al. Leipzig: Leipziger Universitetsverlag, 2016. P. 245-263.

27. Asheichyk V., Vaitovich A. A Late Neolithic Burial from the Drazdy 12 Site in the Upper Neman Region (Western Belarus) // Lietuvos Archeologija. 2016. T. 42. P. 105-125.

28. Чарняўскі М.M. Неаліт Беларусі: праблемы перыядызацыі і храналогіi // Współnota dziedzictwa kulturowego ziem Białorusi i Polski / red. A. Kośko. Warszawa: Ośrodek Ochrony Dziedzictwa Kulturowego, 2004. S. 99-118.

29. Gawrońska J. Elementy kultury amfor kulistych w wytwórczości ceramicznej społeczności kultury rzucewskiej na podstawie wybranych zespołów mikroregionu Niedźwiedzióweckiego // Światowit. 2002. T. 4 (65). Fasc. B. S. 35-56.

30. Kryvaltsevich M. Die Rolle der Kugelamphorenkultur bei der Entwicklung der Gesellschaften des oberen Dnjeprgebietes // Lehren-Sammeln-Publizieren. Dem
Hochschullehrer, Museumsmann und Verleger HansJügenBeierum 60. Geburtstagvon Freunden und Kollegengewidmet / J. Beran et al. Leipzig: Leipziger Universitetsverlag, 2016. P. 231-244.

31. Крывальцэвіч М.М. Новыя вынікі даследавання позняга неаліту - пачатку эпохі бронзы ў Заходнім Палессі // Na rubieży kultur: Badania nad okresem neolitu i wczesną epoką brązu / pod red. U. Stankiewicz i A. Wawrusiewicza. Białystok: Instytucja kultury woj. Podlaskiego, 2011. S. 207-217.

32. Крывальцэвіч М.M. Азярное-1 - паселішча эпохі бронзы на поўначы Палесся. Мінск: ІГ НАНБ, 1999. $108 \mathrm{c}$.

33. Wawrusewicz A. Taksonomiczne podstawy identyfikacji tradycji kultury pucharów lejkowatych w środowisku strefy leśnej Europy Wschodniej. Perspectywa subneolitu kontynentalnego // Матэрыялы па археалогіi Беларусі. 2010. Вып. 18: Даследаванні каменнага і бронзавага вякоў. С. 131-146.

34. Крывальцэвіч М. Да праблемы ўзнікнення «Тшцінца» на поўдні Беларусі // «Trzciniec» - system kulturowy czy interkulturowy process? / red. A. Kośko, J. Czebreszuk. Poznań: Wyd. Poznańskie, 1998. S. 345353.

35. Makarowicz P. Rola społeczności kultury iwieńskiej $\mathrm{w}$ genezie trzcinieckiego kręgu kulturowego (2000-1600 BC). Poznań: Uniwersytet im. A. Mickiewicza w Poznaniu, 1998. $454 \mathrm{~s}$.

36. Białowarczuk M., Gawrońska J. Kultura amfor kulistych w przemianach późnego neolitu i wczesnej epoki brązu w północno-wschodniej Polsce // Na rubieży kultur : Badania nad okresem neolitu i wczesną epoką brązu / pod red. U. Stankiewicz i A. Wawrusiewicza. Białystok: Instytucja kultury woj. Podlaskiego, 2011. S. 109-120.

37. Зерницкая В.П., Симакова Г.И., Павлова И.Д. Признаки хозяйственной деятельности человека в пыльцевых спектрах голоцена Беларуси // Гістарычна-археалагічны зборнік. 2001. Вып. 16. С. 5-19.

38. Калечыц А.Г. Пераход да вытворчай гаспадаркі на тэрыторы Беларусі (шляхі i час) Od neolityzacji do początków epoki brązy. Przemiany kulturowe w międzyrzeczu Odry i Dniepru między VI i II tys. przed Chr. Archaeologia Bimaris. T. 2 / red. J. Czebreszuk, M. Kryvaltsevič, P. Makarowicz. Poznań: Wyd. Poznańskie, 2001. S. 29-42.

39. Калечыц А.Г., Чарняўскі М.M. Плямёны на тэрыторы Беларусі ў новым каменным веку (неаліце) // Гісторыя Беларусі: У 6 т. Т. 1. Старажытная Беларусь: Ад першапачатковага засялення да сярэдзіны XIII ст. / рэдкал.: М. Касцюк (гал. рэд.) і інш. Мінск: Экаперспектыва, 2000. С. 34-52.

40. Щеглова В.В., Чернявский М.М. Фауна из могильника культуры шаровидных амфор у поселка Красносельский Волковысского района // Доклады АН БССР. 1976. Т. 20, № 7. С. 627-629.

41. Piličiauskas G., Asheichyk V., Osipowicz G., Skipitytė R., Varule L., Kozakaitė J., Kryvaltsevich M., Vaitovich A., Lakiza V., Šapolaitė J., Ežerinskis Ž., Pamazanau M., Lucquin A., Craigh O.E., Robson H.K. The Corded Ware culture in the Eastern Baltic: New evidence on chronology, diet, beaker, bone and flint tool function // Journal of Archaeological Science: Reports. 2018. Vol. 21. P. 538-552.

42. Balcer B. Wytwórczość narzędzi krzemiennych w neolicie ziem Polski. Wrocław-Warszawa-Kraków: Wyd. PAN, 1983. $338 \mathrm{~s}$. 


\title{
THE ROLE OF THE GLOBULAR AMPHORA CULTURE IN THE DEVELOPMENT OF THE UPPER NEMAN COMMUNITIES
}

(C) 2019

\author{
Vaitovich Aliaksandra Uladzimirauna, candidate of historical sciences, \\ associate professor of the Department of Archaeology and Special Historical Disciplines \\ Belarusian State University (Minsk, Republic of Belarus)
}

\begin{abstract}
The paper discusses the problems of the Globular Amphora Culture (hereinafter the GAC) in the Upper Neman region. According to the proposition of M. Shmyt the sources related to the GAC have been divided in two groups. The first group is made up of the so-called pure sources i.e. the materials directly related to the GAC although hypothetically at times. It includes cemeteries, flint mines and workshops as well as finds of the quadrangular ground flint axes and chisels. The second group comprises so-called syncretic sources associated with the broad understood GAC traditions. The traits genetically linked to the GAC could be identified in materials of the Neman Culture as well as the local groups of the Corded Ware culture's Range. The presence of the GAC people and traditions in the area in question is dated to the second quarter III - first quarter II BC. Two main forms of transfer the GAC traditions have been distinguished. Firstly, the Upper Neman region was the territory of the direct contacts between the GAC people and the local populations. Secondly, the GAC elements had been distributed in the synthesized forms. The major source of the synthesized GAC traits was the Rzucewo Culture as well as the Middle Dnieper Culture. The prospects of the archaeological research are discussed. On the current stage of the research, the issue of the chronology of the GAC traditions spreading in the area in question requires a more detailed study. Top priority should also be given to a thorough investigation of the GAC role in the socio-economic transformation of the Upper Neman population in the III - the beginning II mill. BC.

Keywords: Globular Amphora Culture; Neman Culture; Corded Ware culture's Range; graves; flint mines; ceramics; ornamentation; flint axes and chisels; cultural traits; traditions; cultural processes; borrowings; farming; Late Neolithic; Republic of Belarus; Upper Neman region.
\end{abstract}

УДК 902. 903. 023

DOI 10.24411/2309-4370-2019-12205

Статья поступила в редакцию 28.01.2019

\section{О ТЕХНОЛОГИИ ИЗГОТОВЛЕНИЯ КЕРАМИКИ ИЗ ЭНЕОЛИТИЧЕСКИХ СЛОЕВ ПОСЕЛЕНИЯ РАКУШЕЧНЫЙ ЯР}

(C) 2019

Васильева Ирина Николаевна, кандидат исторических наук, старший научный сотрудник научно-исследовательской части Самарский государственный сочиально-педагогический университет (2. Самара, Российская Федераџия)

Аннотация. В работе представлены итоги технико-технологического анализа керамики из энеолитических слоев поселения Ракушечный Яр, расположенного на о. Поречный (р. Дон, Ростовская обл., Российская Федерация). Методологической основой проведенного исследования является историко-культурный подход к изучению древней керамики, разработанный в российской археологии А.А. Бобринским. Методы: бинокулярная микроскопия, трасология и эксперимент (физическое моделирование). Микроскопическому изучению был подвергнут 141 образец керамики (условно отдельных сосудов) из слоев №№ 5-2 Ракушечного Яра. Полученная технологическая информация позволила реконструировать приемы и способы изготовления энеолитической посуды на всех ступенях производства в рамках подготовительной, созидательной и закрепительной стадий гончарной технологии. Базируясь на этих данных, в статье дана общая характеристика энеолитического гончарства. Был осуществлен сравнительный анализ гончарной технологии неолитического и энеолитического населения, обитавшего на стоянке Ракушечный Яр. По его итогам выделены черты сходства и различия энеолитических и неолитических гончарных традиций. Особое внимание уделено вопросу о возможных истоках новых традиций, получивших распространение в период энеолита. К ним относятся традиции отбора илистых глин, введения в формовочные массы искусственных добавок: дробленой раковины, пуха птиц, песка.

Ключевые слова: Нижнее Подонье; поселение Ракушечный Яр; неолит; энеолит; керамика; историкокультурный подход к изучению керамики; бинокулярная микроскопия; трасология; эксперимент; гончарная технология; культурные традиции; сравнительный анализ энеолитических и неолитических гончарных традиций.

Введение

Суть многих проблем современной археологии (в том числе - выделения культурных областей, горизонтов, типов эпохи неолита, археологических культур энеолитического периода, а также обоснования перехода от неолита к энеолиту) зачастую сводится к аргументированному извлечению информации из имеющихся археологических источников и доказательной интерпретации полученных данных, т.е. к выбору методики. Среди российских археологов общепринятым является мнение, что наиболее массовым и информативным источником в реконструкции 